KYKLOS, Vol. 57 - 2004 - Fasc. 4, 505-518

\title{
Coase Theorem and the Taiwan Strait Conflict
}

\author{
Bingyuan Hsiung*
}

\section{INTRODUCTION}

In the world of Robinson Crusoe, there are no interpersonal conflicts or confrontations, at least before Friday shows up. The world of Robin Crusoe, however, is a fictional one, for since the dawn of human history, there have been endless conflicts of one sort or another. Correspondingly, there are also countless ways, civilized as well as non-civilized, to deal with conflict.

This short paper analyzes one civilized measure in dealing with conflict, and theoretical findings are employed to help resolve the Taiwan Strait Conflict. The structure of the present paper is fairly simple: Section I is the introduction, followed by a theoretical analysis of the Coase Theorem in Section II; Section III presents an application of the theoretical findings, Section IV derives the implications of the analysis, and the final section concludes the paper.

\section{COASE THEOREM}

In the economics literature there are two famous procedures, both civilized, to deal with either potential or real conflict. One was suggested by Nobel Laureate Harsanyi $(1953,1954)$ - the so called veil of ignorance apparatus ${ }^{1}$. Specifically, one can imagine that a representative individual is behind a veil such that $\mathrm{s} / \mathrm{he}$ is ignorant of his or her future position once the veil is lifted. As such, the

* Professor, Department of Economics, National Taiwan University, Taipei, Taiwan; Visiting Professor, Department of Economics and Finance, City University of Hong Kong, Hong Kong, email: hsiung@ntu.edu.tw. I thank Steve Tsang for fruitful discussions and am indebted to Patrick Gunning, Yew-Kwang Ng, Nuno Garoupa and Ruth Taplin for constructive comments. Financial support from the National Science Council of Taiwan (ROC) as well as research assistance of Deborah Y.F. Chen are also gratefully acknowledged.

1. Rawls (1971) may have been the first to use the term of the veil of ignorance, but the idea was clearly indicated in the two papers by Harsanyi. In addition, Buchanan and Tullock (1962) employed the idea of the veil of uncertainty which was later cited by Rawls. See Dworkin (1977) for a critique of Rawls's analysis. 
representative individual is likely to design a reasonable contract so as to deal with interpersonal conflict that will inevitably arise in the future.

The second procedure to resolve conflict peacefully is also related to a Nobel Laureate, Ronald Coase. In particular, when two parties are engaged in a dispute, one can ask a hypothetical question: what would happen if the parties fall in love and get married? How would the couple, presumably with their interests being merged now, deal with the initial dispute? That is, when two parties are in dispute, one can employ the single-owner test to analyze the issue at hand $^{2}$. If a single owner assumes ownership of the conflicting interests, then $\mathrm{s} /$ he can re-examine the joint interests anew. For instance, one can imagine that the polluting upstream factory and the polluted downstream factory are owned by the same person, or that the residents nearby an airport are also the shareholders of the airlines using the airport, or that the captain of a cargo ship in the storm assumes that he is the owner, though temporarily, of both the ship and the cargo.

As such, by employing the single-owner conceptual device, it may be easy to find the best way to utilize resources concerned so as to maximize the value of production. This essentially echoes Coase's main argument in his 1960 paper on social cost that in assigning property rights, the value of production should be maximized. Consequently, the ingenious single-owner apparatus helps make the Coase Theorem operational in dealing with practical problems in the real world, the world with positive transaction costs. Previous discussions and applications of the single-owner device, however, have implicitly made one important assumption. That is, beyond and above the parties in dispute, there is an overriding, higher authority that can pass out a resolution and implement it. For instance, the courts, by employing the single-owner device, may decide that the airport can be built or expanded but the residents are to be compensated properly. Similarly, the courts, by employing the single-owner reasoning, would allow the captain of the cargo ship in a storm to take expedient measures, e.g., throwing overboard some of the cargo to lighten the ship and then having the losses shared by the cargo owners afterward ${ }^{3}$.

But in Coase's 1960 paper, he neither assumed implicitly nor indicated explicitly the existence of this higher authority. By contrast, what he relied on was that the parties in the dispute would take the proper moves based on their selfinterested considerations! And when he makes a defense of the Coase Theorem in the 1988 collected volume, he specifically explains that the parties involved

2. Baxter and Altree (1972) introduced the single-owner device first.

3. See Epstein (1993) for an elaboration of the single-owner device and Hsiung (2000) for a critique of Epstein's analysis. 
would normally find a mutually beneficial solution by themselves ${ }^{4}$. It is clear, however, that even though the single-owner device is helpful in analyzing conflict, its practicality depends crucially on the particular conditions concerned. If there are no higher authorities to rely on, then for the device to be operational, the parties' considerations based on self-interest must come into play. Unless the proposed measure satisfies the parties' self-interest, it will not be accepted by them and become reality. But this in turn poses a new question. If the proposed measure satisfies the self-interest of the parties in the dispute, then why would they have come to their awkward positions in the first place? Or if they have arrived into the present situation involuntarily, they should have adopted the measure to resolve the dispute long ago. This means that a measure that would be accepted by the parties based on their self-interest often implies a change of perspective for the parties. That is, the parties would come to see things in a new light, realizing that accepting the proposed measure is beneficial to their self-interest as perceived from the new angle.

This simple understanding is vividly illustrated by a famous chapter in Mencius, an ancient Chinese treatise next in importance to the Analect. When Mencius, the man of wisdom and intellectual heir to Confucius, comes to visit King Huei of Liang, the king asks him what he has brought with him that would benefit Liang? Mencius replies that he has brought with him not worldly benefits but the un-worldly virtues of benevolence and righteousness. Then, he argues forcefully that it is in the king's interests to pursue benevolence and righteousness. Thus, while Mencius employs a vocabulary that is different from others, he nonetheless preaches to King Huei's self-interested considerations.

At the beginning of the twenty-first century, the conflict across the Taiwan Strait is undoubtedly one of the most important confrontations on earth ${ }^{5}$. Since there are no higher authorities to rely upon, are there any ingenious measures to resolve the conflict that would be acceptable to the parties concerned based on their self-interested considerations? This is the issue that will be taken up in the next section.

4. Specifically, Coase (1988, p. 161) states that, 'However, there is good reason to suppose that the proportion of cases in which no agreement is reached will be small'.

5. Tsang (2000) outlines a detailed peace proposal to resolve the conflict. For a recent analysis of the delicate situation of the conflict, see Campbell and Mitchell (2001). 


\section{THE TAIWAN STRAIT CONFLICT}

To employ the single-owner device to deal with the Taiwan Strait Conflict, a few facts are to be noted before a resolution is proposed. Economically speaking, Taiwan has a population of 22.5 million in 2002, produces a GNP of approximately 289.3 billion in US dollars, and depends heavily on international trade. By contrast, China has a population of 1280 million, 57 times that of Taiwan, in $2002^{6}$, a GDP of 1266 billion in US dollars, 4.4 times that of Taiwan ${ }^{7}$, and a geographical area 267 times that of Taiwan ${ }^{8}$. In addition, China is the largest single market in the world and, with its current pace of economic development, will soon become one of the, if not the, most important players in world economy. Politically, the Republic of China (ROC) in Taiwan was founded by Dr. Sun Yet-Sen in 1912, and the People's Republic of China (PRC) in mainland was founded by Chairman Mao Ze-Dong in 1949. As such, the ROC has a history of 92 years, and the PRC has a history of 55 years. Compared with the written history of the Chinese civilization of over three thousand years, both political organizations are relatively young, to say the least.

Based on the facts as stated above, one now faces the following questions: Considering the conflict across the Taiwan Strait, what are the combined, or joint, interests of the two sides? If and when the interests are identified, then how are the interests to be pursued? Conceptually speaking, both the ROC and the PRC are in essence political configurations. The single-owner that encompasses the two is the Chinese culture, the Chinese civilization, or the Chinese community. These terms are hard to define precisely but convey similar meanings. The fundamental interests of the Chinese culture, Chinese civilization, or Chinese community are obviously to survive and prosper in the competition among contemporary cultures, civilizations, or communities. This would mean that the spoken and written languages, the ways of life, customs, traditions, beliefs and the value system that are associated with the Chinese culture are to be preserved and extended into the future. To preserve a culture and for it to prosper there must be a proper mechanism that would maintain its vigor and avoid stagnation or decay.

The Chinese history, long as it has been, has been marked by frequent changes of various dynasties. The great dynasties such as Song, Tang, and Han, however, existed for a mere three to four hundred years at most, and the under-

6. See Statistics Executive Yuan, http://www.dgbas.gov.tw/dgbas03/bs8/index.htm.

7. Also see Statistics Executive Yuan, http://www.dgbas.gov.tw/dgbas03/bs2/91 chy/catalog.htm.

8. The numbers can be found in Your Nation, www.your-nation.com, and the source of the figure is based on CIA World Factbook ' 98. 
lying reason is fairly simple. The dynasties have prided themselves in being the single, dominant empire in the Center of the world - the very word China literally means The Central Country in Chinese! As such, when the institutions that have been installed at the beginning of the dynasties started to decay, the liveliness of the dynasties gradually evaporated and the dynasties themselves finally came to an end; new dynasties started from anew and the cycle continued. Given this historical background, when the Chinese people on both sides of the Taiwan Strait are gaining strength economically, it may be time for the two sides to think about the ultimate task of preserving the Chinese in the long run. Specifically, the question is to find a proper way to develop a competitive mechanism within the Chinese community. The issue in fact has been raised by various Chinese economists such as Cheung (1988) and Yang (2001).

Practically speaking, the main political organizations, the PRC and the ROC, are to be responsible for such an endeavor, and considering their differences in size and strength, it is clear that the PRC is to be the dominant player. The question remains, however, as to how to find a feasible solution for the PRC. Within mainland China, there are concerns for security and political sovereignty, and as a result it would be relatively difficult to implement a mechanism that would generate cultural competition within the unified geographical area. The firmly grasped belief in unification only enhances this tendency. By contrast, Taiwan (ROC), separated by the Taiwan Strait since 1949, offers a rare chance inadvertently. In particular, considering the historical background and current situation, both sides might find the principle of 'One China, Two Republics' a middle ground that is acceptable to both sides.

Specifically, 'One China' refers to the fact that there is a distinct Chinese culture shared by both the PRC and ROC; 'Two Republics' refer to the People's Republic of China and the Republic of China. With respect to the PRC, it has always maintained the 'One China' policy, but in the 1992 Shanghai Communique reached by representatives from both sides, it was agreed that 'There is only one China, but the term is to be interpreted by the two sides respectively'. The implication is that the PRC actually accepted that the term 'China' is subject to different interpretations. One possibility is obviously that there is a Chinese cultural tradition and politically the tradition may assume different configurations of which the PRC is just one of many. As such, the first half of the principle of 'One China, Two Republics' would negate any potential hostility toward Taiwan the PRC might have. Alternatively, the second half of the principle, 'Two Republics', merely reflects the fact that since 1949 both sides have enjoyed sovereign power over their respective territories. It also captures the sentiment generally shared by people in Taiwan that they would like to maintain the status quo and keep their ways of life. Consequently, the principle of 
'One China, Two Republics' accommodates realities on both sides across the strait - each side has its own give-and-take in this compromise. More concretely, as the PRC is in the dominant position to shape the relationship across the strait, it could take the initiative in implementing the principle of 'One China, Two Republics'. Specifically, the PRC, in light of the concern for its own long term interests, can announce unilaterally that it would not resort to force and take military action against Taiwan.

What if Taiwan seeks independence following the PRC's announcement, one is tempted to ask. This would indeed be a natural concern for most people, but the point is to see beyond the immediate independence movement, for even if this does come about, it is only the initial scenario. It is more important to predict the scenarios that follow. Assuming that Taiwan indeed declares independence following the PRC's announcement of the no-military-action policy. Since independence would only be a political, nominal, and organizational adjustment, Taiwan would still be part of the Chinese community in other respects, including language, customs and traditions, etc. Moreover, Taiwan's economic dependence on the PRC is increasing with each passing day, as such it is simply not likely that the two sides would become detached economically. The most natural trajectory of development would be that, after a few decades of economic growth, Taiwan and the PRC would have a close relationship, one that is similar to the relationships among the European Union countries or that between the US and Canada. The parties would have a mutually beneficial relation in various aspects, but at the same time they would maintain their own, separate identities. The major advantage for the PRC to induce Taiwan to be more autonomous and independent is that a mechanism to ensure competition is purposefully installed within a culture. In so doing, Taiwan's various experiences in the economic as well as political spheres would become a reference point, a reminder, a benchmark, or a yardstick for the PRC. For future generations of the Chinese, the competition between Taiwan and China across the strait would be a guarantee of the endurance of the Chinese culture.

Moreover, in the words of Chairman Mao, the current conflict is a conflict within the (Chinese) people, and not one that is between enemies. The real competitors, or enemies, the PRC faces are other cultures and traditions. As such, for the PRC the conflict between Taiwan and the PRC is essentially more apparent than real, when compared with the potential competition from other cultures. That is, even if the PRC's non-military policy results in Taiwan declaring independence, it is beneficial to the Chinese culture, and thus to the PRC. Considering the scale of the PRC's economy, as compared to that of Taiwan, it is more than evident that the PRC is in the dominant, leading position. By following this line of reasoning to its logical conclusion, it is obvious that the PRC 
does not have to worry about Taiwan's tendency to seek independence. On the contrary, it is only when the PRC sticks to the unsound, self-defeating logic of the 'great unification', which has been proved to be fatal repeatedly by history that the PRC is inviting trouble.

When the PRC announces the non-military policy towards Taiwan, the strongest opposition is likely to come from the military, the People's Liberation Army. The PRC's military establishments have been the staunchest supporter for unifying the PRC and Taiwan by force, but two factors are to be considered. First, if the PRC employs military measures against Taiwan, then the People's Liberation Army will be guilty of the sin of Chinese fighting against Chinese, resulting in bloodshed between brothers, so to speak. Secondly, even if the military actions turn out to be successful, both the PRC and Taiwan are likely to suffer heavy losses and thus reduce the competitiveness of the Chinese.

Consider now the involvement of the US. It is clear that the US is an important factor in influencing the relationship between Taiwan and the PRC, and that the US has its own strategic considerations. In the Taiwan Strait Conflict, as it currently stands, it is beneficial to the US to adopt a two-part strategy. On the one hand, the US officially supports the PRC's one-China policy and opposes Taiwan's move towards independence; on the other hand, however, the US has stood behind the democratic Taiwan, and constrains the PRC's expanding influence by making sizable arms sales to Taiwan ${ }^{9}$. Once the PRC gives up the option of taking military actions against Taiwan, the tension across the Taiwan Strait is going to subside. Taiwan will no longer need to spend large sums of money on arms, and as a result the economy will get a healthy boost. Concurrently, without the military threat from the PRC, Taiwan's reliance on the US will decline, and consequently the constraint the PRC faces in the Pacific area imposed by the US through Taiwan will also be reduced. In this scenario, the long-term interests of the US would not lie in arbitraging the conflict across the Taiwan Strait but in enjoying a stable, prosperous relationship between the PRC and Taiwan. The reasoning can be illustrated with the help of Figure 1 below.

The current situation, the status quo, is represented by frame 2, where Taiwan is not seeking independence and is getting help from the US. This is the position preferred by the US. The independence movement supported by some Taiwanese people is to move from the status quo to frame 1, where Taiwan will become an independent country with the help of the US. Mainland China's

9. It is interesting to notice that Taiwan's defense budget accounts for over $20 \%$ of the entire government budget; in comparison, Israel's defense budget accounts for only $16 \%$ of its government budget. See The Defense White Papers (2000, pp. 105-108). 


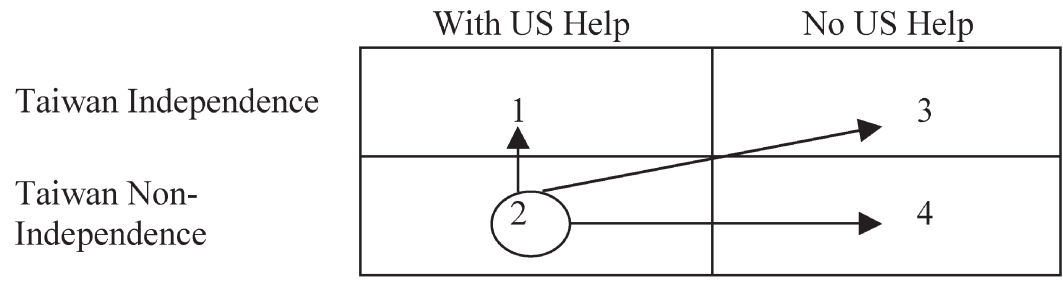

hope is that the situation will move from the status quo to frame 4, so that Taiwan will not seek independence and it will not be getting help from the US. The present paper argues for a move from the status quo to frame 3, where Taiwan will become an independent country with help from not the US but Mainland China ${ }^{10}$.

In sum, there are various ways to resolve a conflict, and measures compatible with self-interested considerations are the crucial factor behind any civilized means of resolution. To resolve the conflict across the Taiwan Strait, one can employ the Coasian single-owner apparatus. Since the PRC has become the dominant factor in shaping the Chinese community, it can, based on the aim of sustaining the Chinese culture and thus guaranteeing a prosperous future for the PRC in the long-run, unilaterally declare that it will adopt a non-military policy towards Taiwan.

\section{DISCUSSIONS}

In this section some issues will be examined that are related to the previous analysis, and the issues can be grouped into two categories: those related to the single-owner apparatus, and those related to the Taiwan Strait Conflict.

Concerning the single-owner device, it is relatively straightforward in identifying Chinese culture as the single-owner of both the PRC and Taiwan, as these two areas constitute two major elements of the Chinese community, with Hong Kong and Singapore being the other important elements. Consequently, this in turn implies that sustaining and expanding the Chinese culture can be seen as the combined interests of the single owner, i.e., the joint or aggregate interests of Taiwan and the PRC. Moreover, due to the unique situation of a significantly dominant PRC, the measure to pursue the combined interests of the

10. I thank Nuno Garoupa for suggesting this figure. 
single-owner is also readily identified. But this may not be true when the single-owner apparatus is applied to analyzing other regional conflicts ${ }^{11}$. Consider for instance the conflict between North Korea and South Korea or that between India and Pakistan. Even though peaceful co-existence in the short-run and prosperity in the long-run can be summarily identified as the combined interests of the parties concerned, it is not at all clear how the interests are to be pursued. In the case of the Korean conflict, it is not clear whether an integrated, unified Korea is better than two separate, competing Koreas. In the case of India and Pakistan, there are no naturally drawn geographical boundaries that can be argued to form the basis on which the combined interests can be pursued. Moreover, in the case of Korea, as in the Taiwan Strait Conflict, the Korean culture can be readily recognized as the single owner of the two Koreas; by contrast, what exactly constitutes the single owner of both India and Pakistan is vague, to say the least ${ }^{12}$.

Alternatively and continuing the above line of reasoning, as far as the applicability of the single-owner apparatus is concerned, the contrast between the Taiwan Strait Conflict on the one hand and the Korean as well as the India-Pakistan conflicts on the other hand is stark. And the contrast also illustrates an aspect of the Coase Theorem that is often neglected. Specifically, the Coase Theorem states that under certain conditions, resource allocation will be efficient, in the sense that the value of production will be maximized. But this implicitly assumes that a measure exists that can be employed to calculate the value of production. It is more than obvious that such a measure may not exist in a variety of situations. That is, the common interests concerning Taiwan and the PRC can be readily identified, but those related to the Koreas and India-Pakistan can not. As such, the previous analysis amply shows that the Coase Theorem is indeed a partial equilibrium and not a general equilibrium analysis, for local, restricted interests are easier to be identified and analyzed, while general, wider interests are difficult to be properly comprehended and handled ${ }^{13}$.

The final point to be made about the single-owner apparatus is that similar considerations can in fact be found in the economics literature, and the relevant discussions can thus be seen as supporting evidence for the arguments put forth in the present paper. In particular, in the industrial organization literature, it is common knowledge that large cooperations often adopt internal pricing to help

11. Cooter (1995) also employs the Coase Theorem to analyze international relations, and the emphasis is on difficulties of clearly defining property rights that involve several countries.

12. What happens in Europe can be argued to be supporting evidence to the argument here. The European Union was formed in 1993 as a single entity to pursue the joint welfare of its members, given their current as well as historical differences.

13. See Hsiung (2003) for an extended discussion of this issue. 
improve the efficiency of resource allocation. Similarly, to avoid the increase of bureaucratic layers within large firms, horizontal instead of vertical expansion has been routinely chosen to maintain the innovativeness and competitiveness of the whole enterprise (the single-owner). That is, the interest of a large organization may be better served by purposefully dividing the whole organization into smaller, competing units ${ }^{14}$.

Consider next some related issues concerning the Taiwan Strait Conflict; a few points can be made. First, in applying the single-owner apparatus to analyze the Taiwan Strait Conflict in the previous section, two assumptions have been made implicitly. The first implicit assumption is that the PRC's economy would grow steadily such that business cycles and other non-economic factors would not become dominant in shaping the relationship across the Taiwan Strait. For if business cycles bring about mass unemployment or a worsening income distribution generates significant social unrest, then anxiety and anger may accumulate to the point where the PRC would take strong or even military action against Taiwan as a means to redirect the internal tension, thus a peaceful solution would become infeasible. The second implicit assumption is that as the PRC's rapid economic development continues, the general public as well as public-policy decision-makers would rely increasingly on economic rationality. In a nutshell, economic rationality means that practical, as opposed to abstract, cost and benefit considerations would become the basis of decisionmaking, private as well as public. There are indications that economic rationality has indeed been increasing within the PRC. For instance, before the PRC shifted to the open-up policy, the economy was relatively underdeveloped and the general public were absorbed by such abstract terms as national pride or historical glory. As a result, the number of medals won in the Olympic games was closely followed, and the medal winners were highly valued by both the PRC government and the general public. As economic development moves up along a more stable path, however, the general public can harvest and enjoy concrete gains from the thriving economic activities. Consequently, Olympic medals and the medal winners have declined in importance. That is to say, as its economy grows continuously, both internal expectations as well as the external globalization process have become forces that shape people's way of thinking within the PRC. As such, economic rationality is expected to increase for the PRC, which would enhance the relevance of the arguments put forward in the present study.

Secondly, in applying the single owner device to analyze the Taiwan Strait Conflict, it was indicated that the single-owner refers to the Chinese civiliza-

14. For instance, see the analysis of Sah and Stiglitz (1986). 
tion encompassing both Taiwan and the PRC. But as a policy suggestion, the focus was on the PRC and not on Taiwan. The imbalance in treatment is a direct result of considering the relative sizes of the two. Economically and militarily, the PRC is clearly in a dominant position. Moreover, Taiwan's economic reliance on the PRC is much higher than the PRC's economic reliance on Taiwan, and the spread of the differences is likely to increase in the future. Specifically, statistics show that Taiwan's export to the PRC as a percentage of its total export went from $2 \%$ in 1987 to over $23 \%$ in 2002 . By contrast, the PRC's export to Taiwan has never exceeded $2 \%$ of its total export for the same period. In addition, among the PRC's trading partners, Taiwan has the highest dependence ratio, reaching $20 \%$ in 2002; Korea has the second highest, with a dependence ratio of $12 \%{ }^{15}$. Therefore, in all likelihood Taiwan will have to surpass ideological obstacles and develop a friendly, mutually beneficial relationship with the PRC before long.

Finally, that political unification and cultural singularization is not necessarily beneficial in the long run is not only supported by Chinese history, it is also evident in the historical experiences of other cultures. Take English as an example. The fact that English is now universally accepted as an international language is not because of a dominant or unified Britain, but because of the cultural diversity made possible by the competitions between and among the US, Canada, Australia, and New Zealand, etc. Therefore, history shows chasing the glory of a unified China is only slightly better than chasing the glory of a rainbow - the glory of a rainbow is illusory; the glory of a unified Chinese empire does exist, but only transitorily so!

\section{CONCLUSIONS}

In this short paper the discussion of the Coase Theorem has been extended and the findings applied to analyze the Taiwan Strait Conflict. As such, it is hoped that new elements have been developed both theoretically and empirically. There is one final point to be made, and it is related to both Coase and the Theorem that bears his name. There has been a unique tie between Coase and the Chinese, as his long lasting friendship with Steven Cheung is well-known, and through Cheung Coase has become arguably the most famous Western economist in the Chinese community. If somehow the Coase Theorem can help resolve the Taiwan Strait Conflict, then it will not only be one of the most influential theorems in economics, it will also be the driving force in resolving one

15. The numbers can be found in Cross-Straits (2002, p. 47). 


\section{of the most important conflicts in human history. If that happens, it will prove again that (economists') ideas move the world!}

\section{REFERENCES}

Baxter, William F. and Lillian R. Altree (1972). Legal Aspects of Airport Noise, Journal of Law and Economics. 15: 1-113.

Buchanan, James M. and Gordon Tullock (1962). The Calculus of Consent. Ann Arbor: University of Michigan Press.

Campbell, Kurt M. and Derek J. Mitchell (2001). Crisis in the Taiwan Strait? Foreign Affairs. July/ August.

Cheung, Steven (1989). San-di-chin-huai (Thoughts on China, Taiwan, and Hong Kong). Taipei: Yuan-Lieo. (in Chinese)

Coase, Ronald H. (1960). The Problem of Social Cost, Journal of Law and Economics. 3: 1-44.

Coase, Ronald H. (1988). The Firm, the Market, and the Law. Chicago: University of Chicago Press.

Cooter, Richard N. (1995). The Coase Theorem and International Economic Relations, Japan and the World Economy. 7(1): 29-44.

Cross-Straits (2002). Taipei: Cross-Strait Common Market Foundation, March. (in Chinese)

Dworkin, Ronald (1977). Taking Rights Seriously. Cambridge, MA: Harvard University Press.

Epstein, Richard A. (1993). Holdouts, Externalities, and the Single Owner: One More Salute to Ronald Coase, Journal of Law and Economics. 36(1): 553-594.

Harsanyi, John C. (1953). Cardinal Utility in Welfare Economics and in the Theory of Risk-Taking, Journal of Political Economy. 61: 434-435.

Harsanyi, John C. (1955). Cardinal Welfare, Individualistic Ethics, and Interpersonal Comparisons of Utility, Journal of Political Economy. 63: 309-321.

Hsiung, Bingyuan (2000). On the Equivalence and Non-equivalence of James Buchanan and Ronald Coase, Journal of Institutional and Theoretical Economics. 156(4): 715-736.

Hsiung, Bingyuan (2003). Reconciling Coase and Buchanan on the Coase Theorem, Journal of Institutional and Theoretical Economics. 159(2): 392-413.

Rawls, John (1971). A Theory of Justice. Cambridge, MA: Harvard University Press.

Sah, Raaj and Joseph E. Stiglitz (1986). The Architecture of Economic Systems: Hierarchies and Polyarchies, American Economic Review. 76: 716-727.

Tsang, Steve (2000). China and Taiwan: A Proposal for Peace, Security Dialogue. 31(3): 327-336.

The Defense White Papers (2000). Taipei: The Ministry of Defense. (in Chinese)

Yang, Xiao-kai (2001). Benefit and Cost of China's Unification, in: Xiao-kai Yang, Papers on Economics. Taipei: Hanlu Publishing House. (in Chinese)

\section{SUMMARY}

The idea of a single-owner who owns the opposing interests of a dispute has been suggested in the literature to make the Coase Theorem operational in resolving dispute. This paper points out that the idea implicitly assumes the existence of an overriding authority, e.g., the Courts, to implement the solution. When such an overriding authority does not exist, a different rationale must be employed to make the single-owner apparatus work. This insight is explored and then applied to help resolve the Taiwan Strait Conflict. Specifically, a 'One China, Two Republics' policy is proposed and its implications illustrated. 


\section{COASE THEOREM AND THE TAIWAN STRAIT CONFLICT}

\section{ZUSAMMENFASSUNG}

In der ökonomischen Literatur wurde die Idee vorgebracht, das Coase Theorem für die Lösung von Konflikten nutzbar zu machen, indem die widerstreitenden Interessen einem einzigen Eigentümer übertragen werden. Im vorliegenden Aufsatz wird aufgezeigt, dass diese Idee die Existenz einer übergeordneten Autorität voraussetzt, z.B. ein Gericht, die dies durchsetzen kann. Wenn es keine solche Autorität gibt, muss das Prinzip des einzigen Besitzers auf andere Weise umgesetzt werden. Dieser Gedanke wird hier erforscht und auf den Taiwan-Strasse-Konflikt angewandt. Insbesondere wird eine Politik des 'ein China, zwei Republiken' vorgeschlagen. Auch werden deren Implikationen aufgezeigt.

\section{RÉSUMÉ}

L'idée d'un propriétaire unique qui possède les intérêts s'opposant dans un conflit a été proposée dans la littérature afin de rendre le théorème de Coase applicable à la solution de conflits. Cet article montre que cette idée présuppose l'existence d'une autorité suprême, p.ex. un tribunal, pour imposer la solution. Si une telle autorité n'existe pas, une autre solution doit être trouvée pour faire fonctionner le principe du propriétaire unique. Ceci est examiné et appliqué au conflit du détroit de Taiwan. En particulier, nous proposons une politique 'une Chine, deux Républiques', dont les implications sont illustrées. 
Copyright of Kyklos is the property of Blackwell Publishing Limited and its content may not be copied or emailed to multiple sites or posted to a listserv without the copyright holder's express written permission. However, users may print, download, or email articles for individual use. 